\title{
An intelligent, automatic body measurement system based on ultrasonic sensor arrays
}

\author{
Qiuhan Wang \\ School of Fashion, Wuhan Textile University, Wuhan 430200, China \\ wqiuhan@wtu.edu.cn
}

ABSTRACT. This paper aims to achieve automatic and efficient measurement of the body in garment customization. Therefore, an intelligent body measurement system was established based on ultrasonic sensor arrays, which can efficiently capture the bust, waist and hip (BWH) information. In the system, the exact distance between the body and the sensor is captured by a pair of ultrasonic sensor arrays; then, the depth information is processed by the BWH generation method, including space coordinate generation, curve fitting and curve integration. The experimental results show that the proposed system can achieve a measuring accuracy of $99.61 \%$, indicating that the proposed system is an ideal tool for garment customization.

RÉSUMÉ. Cet article vise à réaliser une mesure automatique et efficace du corps dans la personnalisation du vêtement. Par conséquent, un système de mesure du corps intelligent a été établit basé sur les réseaux de capteurs ultrasoniques, qui peuvent capturer efficacement les informations concernant le buste, la taille et la hanche $(B W H)$. Dans ce système, la distance exacte entre le corps et le capteur est capturée par une paire de réseaux de capteurs ultrasoniques; ensuite, les informations de profondeur sont traitées par la méthode de génération $B W H$, y compris la génération de coordonnées spatiales, l'ajustement de courbes et l'intégration de courbes. Les résultats expérimentaux montrent que le système proposé peut atteindre une précision de mesure de 99,61\%, indiquant que le système proposé est un outil idéal pour la personnalisation du vêtement.

KEYWORDS: garment customization, body measurement, ultrasonic sensor array, curve fitting. MOTS-CLÉS: personnalisation du vêtement, mesure du corps, réseau de capteurs ultrasoniques, ajustement de courbes.

DOI:10.3166/ I2M.17.625-639 @ 2018 Lavoisier

Instrumentation, Mesure, Métrologie $-n^{\circ}$ 4/2018, 625-639 


\section{Introduction}

Custom-tailored garment is now in vogue thanks to the explosive growth in apparel demand and the increasingly diverse tastes in clothing (Zhu et al., 2017; Sun et al., 2017). Before customization, it is important to obtain the accurate sizes of the bust, waist and hip (BWH) of the consumer. The traditional manual tape measurement is cheap, easy to implement and widely adopted in the clothing industry. However, there are many disadvantages with this method: it is inefficient and costly to measure a large group of consumers, the measuring accuracy purely relies on the experience of the dressmaker, and it is impossible to acquire the 3D data of the body (Uhm et al., 2015; Liu et al., 2016; Petrak et al., 2017). Another limitation of the traditional approach is that the tape must be in contact with the body of the consumer. However, it is unsuitable to make that contact under special circumstances.

With the development of measurement techniques, some non-contact measurement methods have emerged to solve the problem (Wang, 2015; Wang, 2015). For example, the 3D measurement technique (Kim et al., 2016; Giachetti et al., 2015) has been applied to body measurement, and proved to support fast and accurate acquisition of a massive amount of data. The classical non-contact measurement methods mainly fall into laser scanning technology, stereo photography and structured light measurement. Developed in the late 1970s, the laser scanning technology uses multiple laser range finders to capture the depth information in different orientations. This approach can achieve a high accuracy in 3D measurement at a high cost. The stereo photography (Akimoto et al., 2013; Chen et al., 2013; Cao et al., 2014) shots two images of the object with cameras from different angles, obtains the depth information from the images, and reconstructs the 3D image of the object based on the depth information and the key points selected from the two images. This technology involves too many steps (e.g. feature point matching, image correction, depth calculation and $3 \mathrm{D}$ reconstruction) and requires heavy computation. What is worse, the accuracy of this method is not desirable because it is difficult to acquire the accurate depth information based on the two images. As a research hotspot, the structured light measurement (Cui et al., 2012; He and Cao, 2011; Huang et al., 2016; Cai et al., 2016) projects structured light onto the object, captures the reflected light by camera, and then computes the space information of the object by the information of the reflected light. Despite its high accuracy, this strategy is too expensive to be widely applied.

To acquire the accurate body data at a low cost, this paper puts forward a novel and efficient body measurement system based on the ultrasonic sensor arrays (Kumar and Furuhashi, 2017; Rabadan et al., 2017). In this system, the depth information between the body and the sensor is captured by ultrasonic sensor arrays; the depth data, coupled with array positions, are used to generate the space coordinates; the BWH data are computed accurately according to the space coordinates. The simplicity and accuracy of the proposed system was verified through experiments.

The remainder of this paper is organized as follows: Section 2 introduces the proposed body measurement system; Section 3 carries out the experiments and analyzes the experimental results; Section 4 discusses about the features of the system 
and the possible improvements; Section 5 wraps up this paper with some meaningful conclusions.

\section{Methodology}

As shown in Figure 1, our body measurement system mainly consists of two models, namely, the measurement model and the fitting model. The former acquires the key data for the derivation of space coordinates, while the latter implements curve fitting, integral computation and BWH calculation.

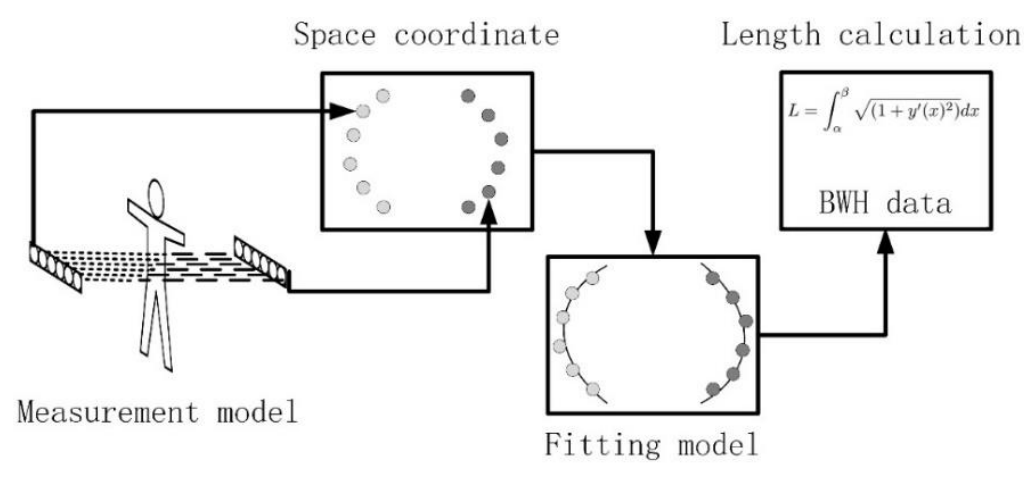

Figure 1. The body measurement system

\subsection{Measurement model}

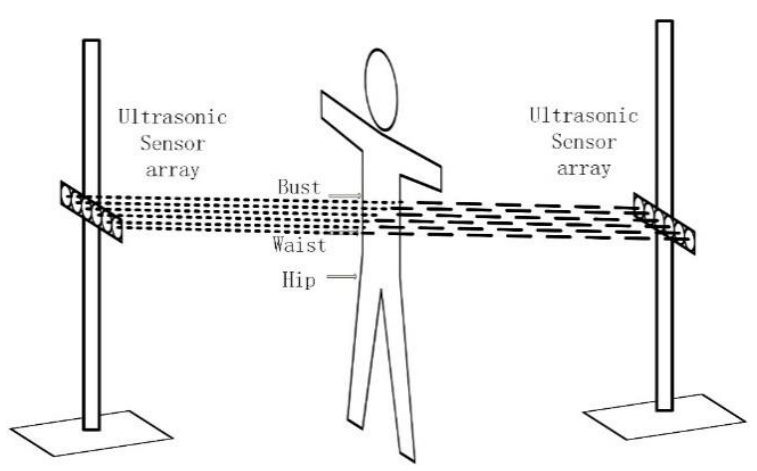

Figure 2. The measurement model 
The accurate acquisition of the depth information is essential to body measurement. It is impossible to determine the space coordinates of the body without the depth information between the body and the sensor. In our system, two ultrasonic sensor arrays at the same height are adopted to scan the BWH of the body. The sketch map of the measurement model is shown in Figure 2 below.

To avoid signal interference, the two ultrasonic sensor arrays scan the body in an asynchronously manner. The front array captures the depth information of the front of the body while the back array captures that of the back of the body. The bust, waist and hip can be scanned together or separately as per actual needs. The captured data are stored in the processing server.

The front and back arrays cannot acquire the accurate depth on the sides of human body, because the body is very thick on both sides. Thus, the edge points of the body are defined by depth hopping. Taking the front depth as an example, the edge points are those with a steep change in the set of depth data captured by the front array; those points between the left and right edges are considered as valid ones for curve fitting.

After obtaining the depth information of the valid points, a space coordinate system (Figure 3) can be set up based on the depth information and the array positions. In the system, the origin is the intersection of the ground and the body centerline, the $\mathrm{x}$ axis points from the right hand to the left hand, and the $\mathrm{y}$ axis points from the front array to the back array.

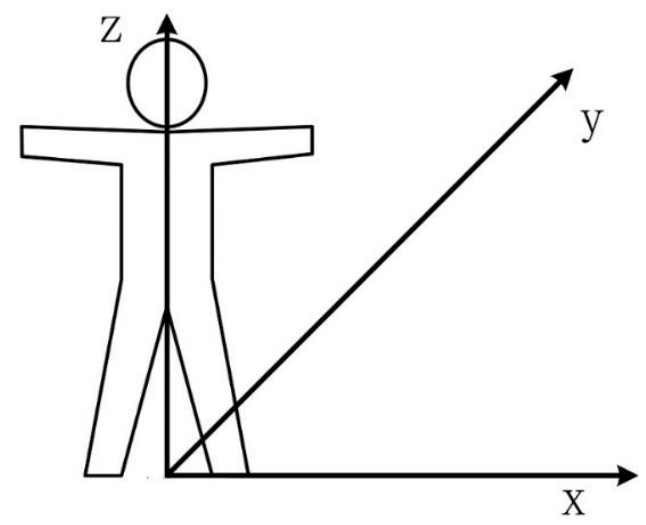

Figure 3. The space coordinate system

Then, the set of space coordinates $\Phi(x, y, z)$ can be described as: 


$$
\Phi(\mathrm{x}, \mathrm{y}, \mathrm{z})=\left[\begin{array}{cccc}
X_{1} & x_{2} & \cdots & x_{n} \\
y_{1} & y_{2} & \cdots & y_{n} \\
z_{1} & z_{2} & \cdots & z_{n}
\end{array}\right]
$$

where $\mathrm{x}, \mathrm{y}$, and $\mathrm{z}$ are the space coordinates of a valid point; $\mathrm{n}$ is the number of the valid points.

\subsection{Fitting model}

The fitting model was designed to generate the BWH data. The core of this model is the curve fitting algorithm. Here, the polynomial fitting (Sekiya and Sugimoto, 2015; Biswas et al., 2016) is adopted to generate curves in light of the features of the valid points. The BWH parameters include the front curve length, the back curve length and the estimated parameter (an empirical value estimated from height and weight). The fitting model is detailed as follows.

Fitting model

Input: The space points $\Phi(x, y, z)$ and the estimated parameter $\zeta$

Output: The BWH data

Step 1: Select a height and obtain 2D space points $\Phi(x, y)$;

Step2: Set the curve $y_{i}(\mathrm{x})=\mathrm{a}_{0}+\mathrm{a}_{1}+\mathrm{a}_{2} \mathrm{x}^{2}+\ldots+\mathrm{a}_{\mathrm{i}} \mathrm{x}^{\mathrm{m}}$;

Step3: Calculate the mean square error

$E\left(\mathrm{a}_{0}, \mathrm{a}_{1}, \ldots, \mathrm{a}_{i}\right)=\sum_{i=1}^{m}\left(\mathrm{a}_{0}+\mathrm{a}_{1} \mathrm{x}+\mathrm{a}_{2} \mathrm{x}^{2}+\cdots+\mathrm{a}_{i} \mathrm{x}^{i}-y_{i}^{i}\right) ;$

Step 4: Calculate the extreme value of parameters $a_{i}(i \in[0,1, \ldots, m])$ as follows:

$$
\begin{aligned}
& \frac{\partial E\left(\mathrm{a}_{0}, \mathrm{a}_{1}, \cdots, \mathrm{a}_{m}\right)}{\partial \mathrm{a}_{0}}=m \sum_{i=1}^{m}\left(\mathrm{a}_{0}+\mathrm{a}_{1} \mathrm{x}+\mathrm{a}_{2} \mathrm{x}^{2}+\cdots+\mathrm{a}_{i} \mathrm{x}^{m}-y_{i}^{m}\right) * 1=0 \\
& \frac{\partial E\left(\mathrm{a}_{0}, \mathrm{a}_{1}, \cdots, \mathrm{a}_{m}\right)}{\partial \mathrm{a}_{1}}=m \sum_{i=1}^{m}\left(\mathrm{a}_{0}+\mathrm{a}_{1} \mathrm{x}+\mathrm{a}_{2} \mathrm{x}^{2}+\cdots+\mathrm{a}_{i} \mathrm{x}^{m}-y_{i}^{m}\right) * \mathrm{x}_{i}=0 \\
& \cdots \\
& \frac{\partial E\left(\mathrm{a}_{0}, \mathrm{a}_{1}, \cdots, \mathrm{a}_{m}\right)}{\partial \mathrm{a}_{i}}=m \sum_{i=1}^{m}\left(\mathrm{a}_{0}+\mathrm{a}_{1} \mathrm{x}+\mathrm{a}_{2} \mathrm{x}^{2}+\cdots+\mathrm{a}_{i} \mathrm{x}^{m}-y_{i}^{m}\right) * \mathrm{x}_{i}^{m}=0
\end{aligned}
$$

Step 5: Obtain the fitted curve $C_{\text {front }}$ and output the length $L_{f r o n t}$;

Step 6: Repeate the above procedure to obtain the fitted curve $C_{\text {back }}$ and output the length $L_{b a c k}$; 


\section{Step 7: Output the BWH data $\mathrm{B} / \mathrm{W} / \mathrm{H}=L_{\text {front }}+L_{\text {back }}+\zeta$}

The space points are divided into front points and back points according to the space coordinates. The two types of points are fitted with the curve fitting algorithm, respectively. The lengths of front and back curves can be calculated as:

$$
L=\int_{\alpha}^{\beta} \sqrt{\left(1+\mathrm{y}^{\prime}(\mathrm{x})^{2}\right)} d x
$$

where $\alpha$ and $\beta$ are the range of $\mathrm{x}$ coordinate of valid points; $d$ is the first-order derivative (Haris et al., 2016) of the fitting function.

\section{Experimental verification}

This section evaluation the performance of the proposed system through experiments, including testing the stability of the ultrasonic sensor array, comparing the polynomial fitting against different fitting methods, evaluating the polynomial fitting with different orders, and analyzing the density effect of the valid points on the fitted curve.

\subsection{Evaluation of array stability}

Considering the importance of depth information in the measurement system, the ultrasonic sensor array was adopted to measure a body at the distances of $40 \mathrm{~cm}, 60 \mathrm{~cm}$ and $100 \mathrm{~cm}$, respectively. Ten measurements were conducted at each distance. The measured data are listed in Table 1 below.

Table 1. Measured data at different distances

\begin{tabular}{|c|c|c|c|c|c|c|c|c|c|c|c|c|c|}
\hline $\begin{array}{l}\text { Real } \\
\text { Dist } \\
\text { ance } \\
(\mathrm{cm})\end{array}$ & 1 & 2 & 3 & 4 & 5 & 6 & 7 & 8 & 9 & 10 & $\begin{array}{l}\mathrm{Me} \\
\text { an }\end{array}$ & $\begin{array}{l}\text { Vari } \\
\text { ance }\end{array}$ & $\begin{array}{l}\text { Accu } \\
\text { racy }\end{array}$ \\
\hline 40 & $\begin{array}{c}40 . \\
01\end{array}$ & $\begin{array}{l}40 . \\
44\end{array}$ & $\begin{array}{l}40 . \\
12\end{array}$ & $\begin{array}{l}40 . \\
55\end{array}$ & $\begin{array}{l}40 . \\
12\end{array}$ & $\begin{array}{l}40 . \\
03\end{array}$ & $\begin{array}{l}40 . \\
06\end{array}$ & $\begin{array}{l}40 . \\
15\end{array}$ & $\begin{array}{c}40 . \\
15\end{array}$ & $\begin{array}{l}40 . \\
48\end{array}$ & $\begin{array}{l}40 \\
211\end{array}$ & $\begin{array}{c}0.04 \\
0\end{array}$ & $\begin{array}{c}99.4 \\
8 \%\end{array}$ \\
\hline 60 & $\begin{array}{l}59 . \\
91\end{array}$ & $\begin{array}{l}59 . \\
67\end{array}$ & $\begin{array}{l}60 . \\
12\end{array}$ & $\begin{array}{l}59 . \\
77\end{array}$ & $\begin{array}{l}59 . \\
86\end{array}$ & $\begin{array}{l}59 . \\
82\end{array}$ & $\begin{array}{l}59 . \\
79\end{array}$ & $\begin{array}{l}59 . \\
68\end{array}$ & $\begin{array}{l}60 . \\
46\end{array}$ & $\begin{array}{l}59 . \\
63\end{array}$ & $\begin{array}{l}59 . \\
871\end{array}$ & $\begin{array}{c}0.06 \\
3\end{array}$ & $\begin{array}{c}99.7 \\
9 \%\end{array}$ \\
\hline 100 & $\begin{array}{l}97 . \\
43\end{array}$ & $\begin{array}{c}98 . \\
50\end{array}$ & $\begin{array}{l}97 . \\
98\end{array}$ & $\begin{array}{l}98 . \\
43\end{array}$ & $\begin{array}{l}98 . \\
43\end{array}$ & $\begin{array}{l}98 . \\
787\end{array}$ & $\begin{array}{c}98 . \\
89\end{array}$ & $\begin{array}{l}98 . \\
44\end{array}$ & $\begin{array}{c}98 . \\
81\end{array}$ & $\begin{array}{c}98 . \\
58\end{array}$ & $\begin{array}{l}98 . \\
436\end{array}$ & $\begin{array}{c}0.19 \\
8\end{array}$ & $\begin{array}{c}98.4 \\
4 \%\end{array}$ \\
\hline
\end{tabular}

It can be seen that the array achieved an accuracy greater than $98 \%$ and the variance of each ten measurements was fairly small. Hence, the array is accurate and stable enough for the measurement demand. 


\subsection{Comparison between different fitting methods}

The polynomial fitting was contrasted against the exponential fitting (Lin and Liu, 2000; Shuan et al., 2016), Fourier fitting (Brooks et al., 2012; Lrenz-Fonfria and Padrs 2004), Gaussian fitting (Juki and Scitovski, 2005; Moammed and Hou, 2016) and sine fitting (Guo et al., 2015; Renczes et al., 2016) through the fitting of the front and back curves. In general, the front curve is shaped as a parabola, while the back curve as the letter W. The curves fitted by the above methods are presented in Figure 4 below.

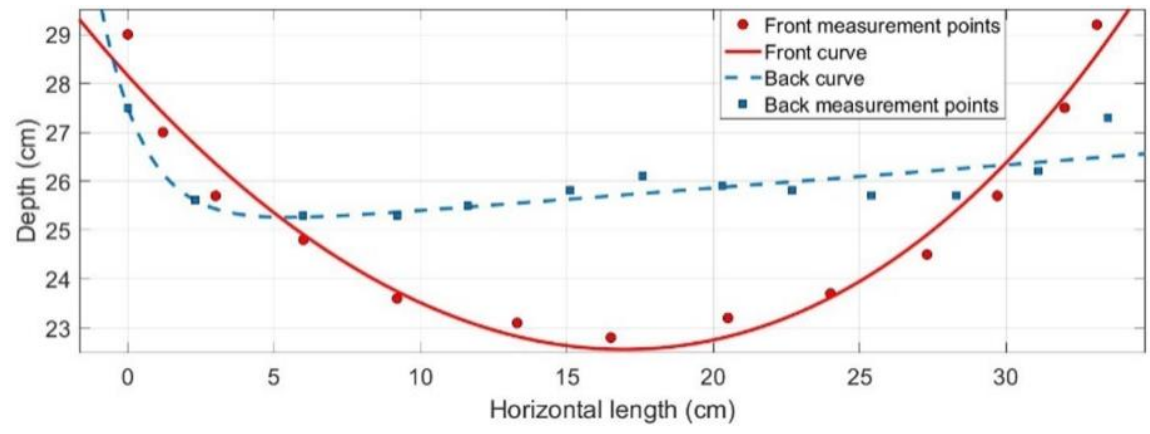

(a) Exponential fitting

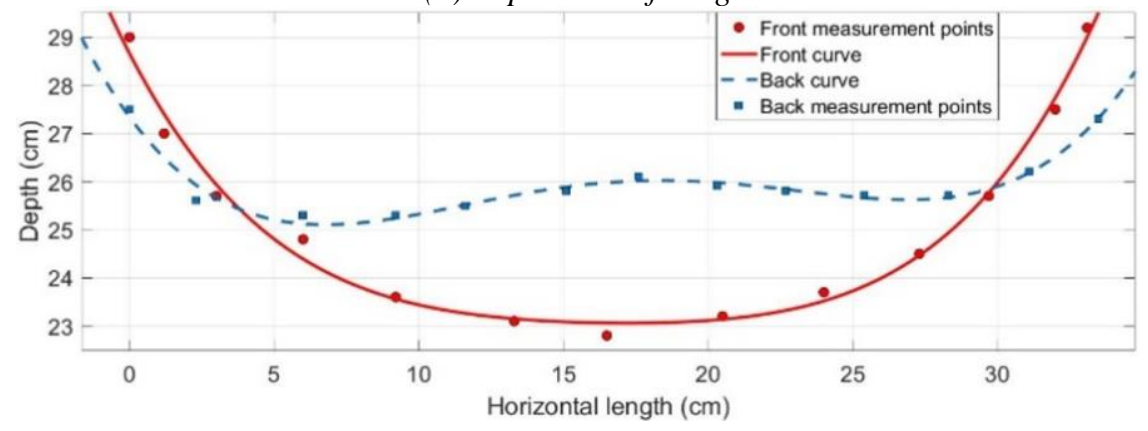

(b) Fourier fitting

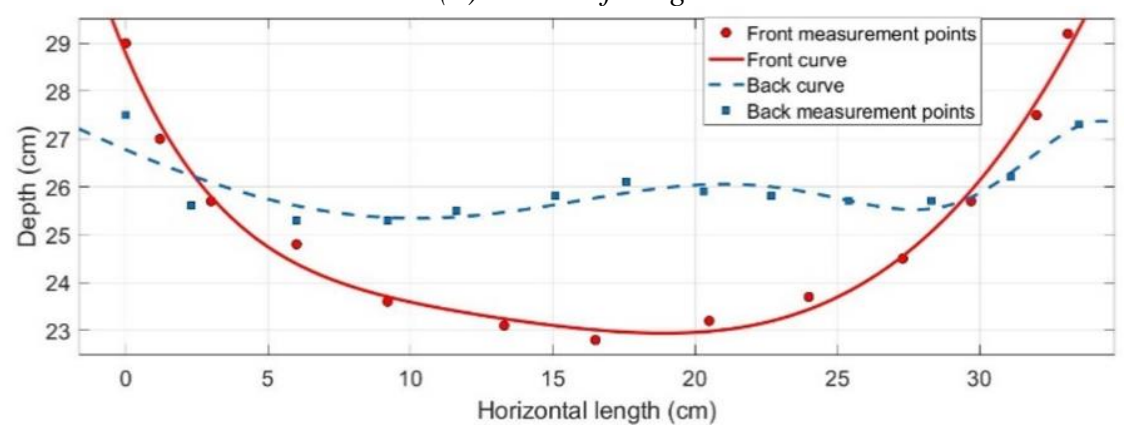

(c) Gaussian fitting 


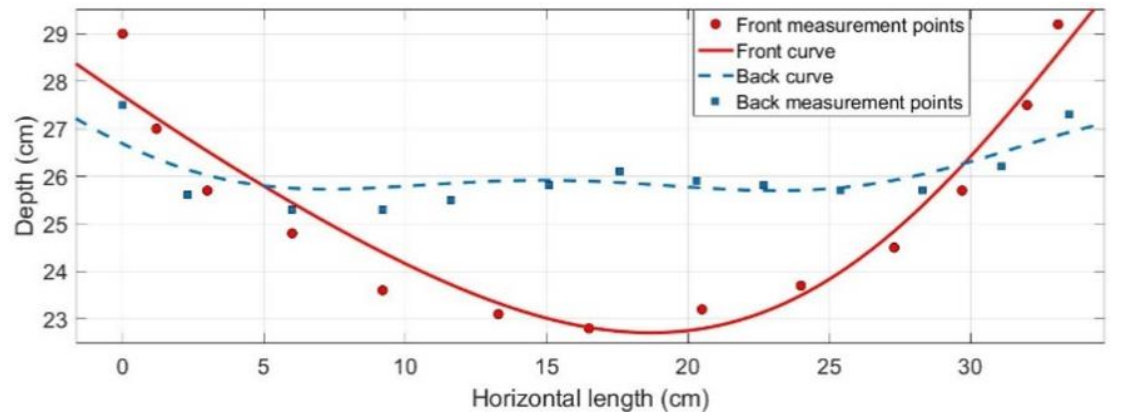

(d) Sine fitting

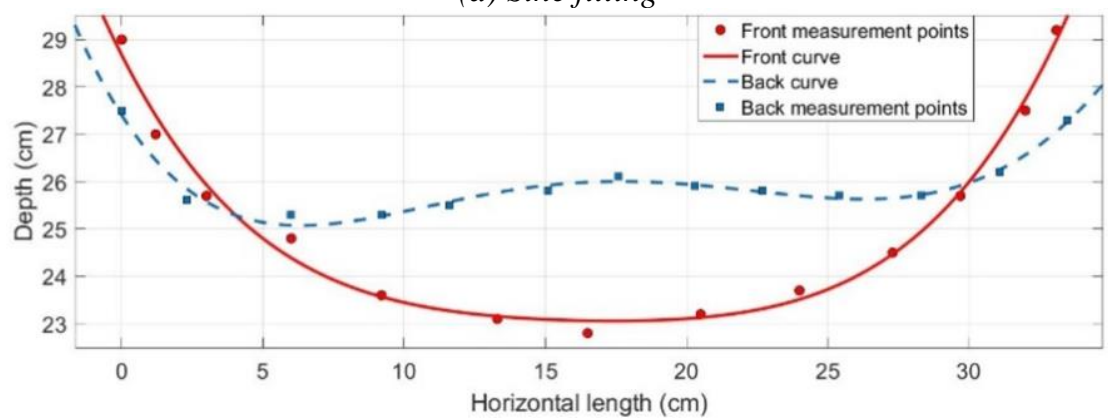

(e) Polynomial fitting

Figure 4. The curves fitted by different methods

As shown in Figure 4, all the front curves were well fitted, and all the back curves were fitted satisfactorily except the one fitted by the exponential fitting. Despite the good performance, the Fourier fitting, Gaussian fitting and sine fitting were not robust enough in the face of different points and prone to the over-fitting problem. In general, the polynomial fitting achieved the best performance without serious over-fitting, which verifies the rationally of polynomial fitting in our system.

\subsection{Evaluation of the polynomial fitting with different orders.}

The polynomial fitting was implemented to fit the front and back curves based on discrete space points. According to the features of the curves, the front curve can be fitted as second- to eighth-order curves (Johnson et al., 2010; Floater, 2006), while the back curve can be fitted as fourth- to eighth-order curves. The curves thus fitted by polynomial fitting are shown in Figures 5 and 6 below. 


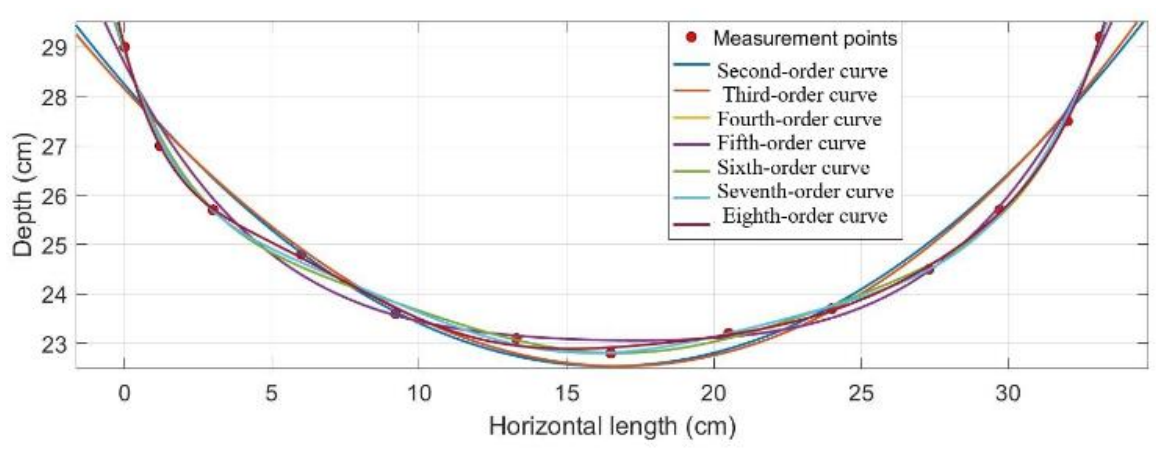

Figure 5. The front curves fitted by polynomial fitting with different orders

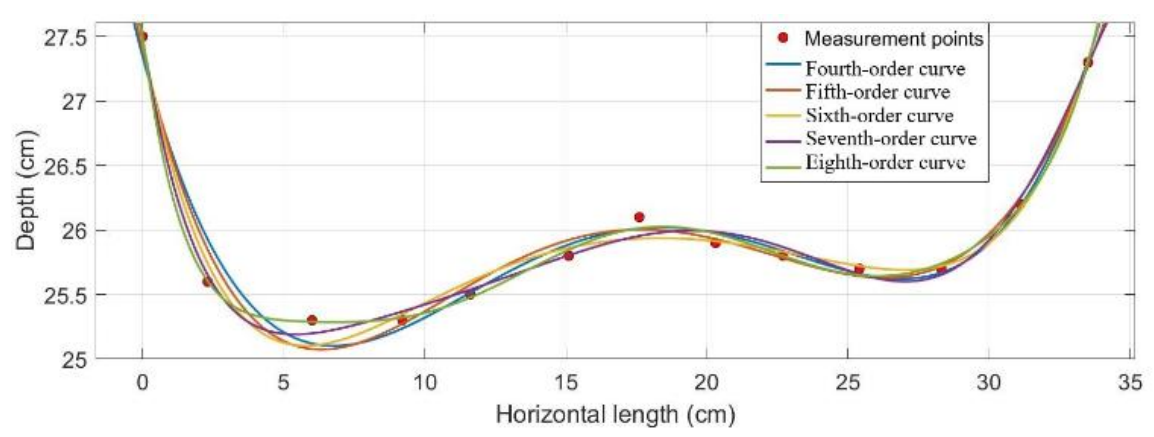

Figure 6. The back curves fitted by polynomial fitting with different orders

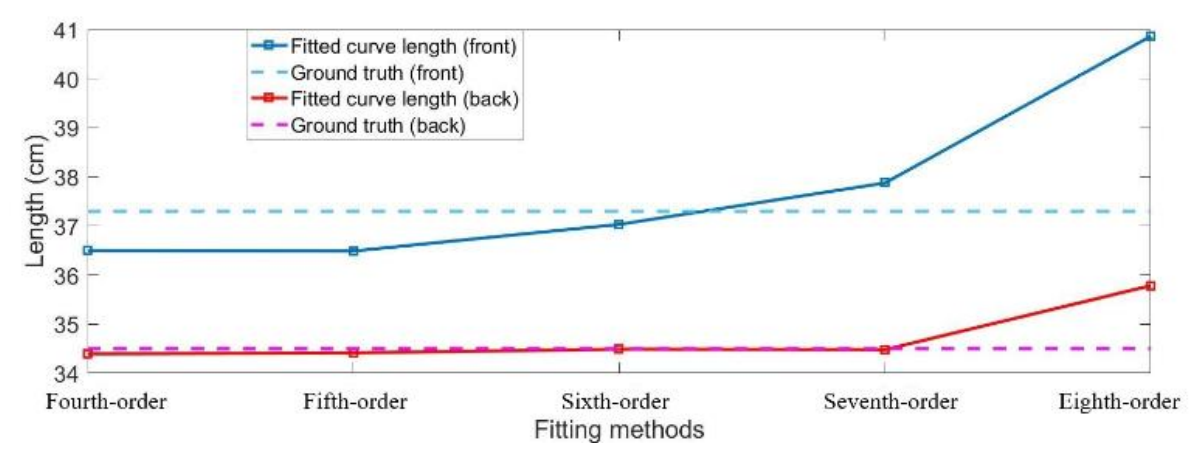

Figure 7. Polynomial fitting results with different orders 
The fitted front and back curves demonstrate the polynomial fitting achieved excellent robustness and prevent over-fitting with any order. There will be serious over-fitting with different orders if the curves are fitted by exponential, Fourier, Gaussian or sine fitting methods.

Next, the length of the fitted front and back curves was calculated to determine the optimal order. The calculated results are illustrated in Figure 7, where the blue and red continuous lines are the length of the fitted front curve and that of the fitted back curve, respectively, and the blue and red dotted lines are the ground truth of the front distance and that of the back distance. It can be seen that the sixth-order curve fitting obtained more accurate results than the other order functions.

According to the fitted curves, the accuracies of the fourth- to eight- order curves were compared in terms of the curve length. The results are presented as Figure 8 . Compared with the ground truths of front and back distances $(37.3 \mathrm{~cm}$ and $34.5 \mathrm{~cm})$, the accuracies of the fourth- to eight- order curves were $98.74 \%, 98.75 \%, 99.61 \%$, $99.23 \%$, and $93.25 \%$, respectively. Overall, the accuracy increased first and then decreased. Obviously, the sixth-order curve fitting is the optimal choice.

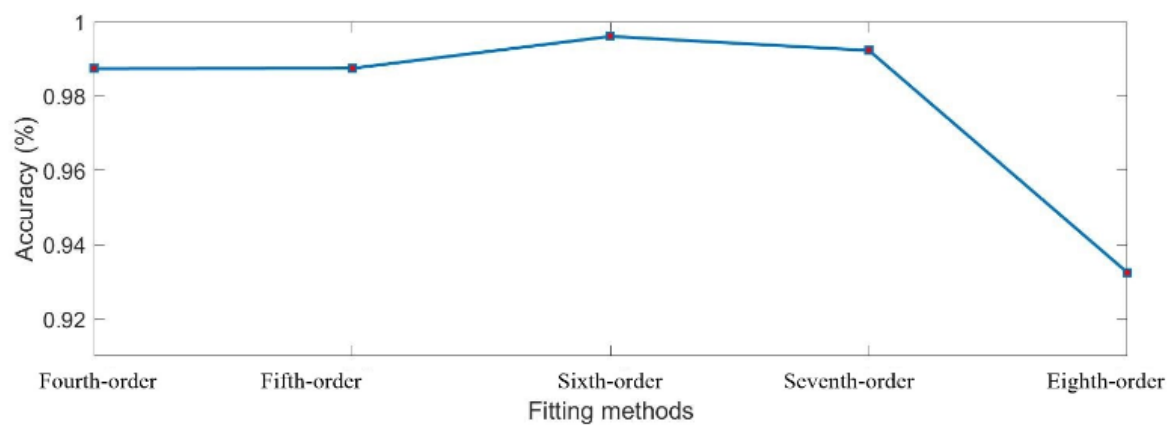

Figure 8. The accuracies of polynomial fitting with different orders

\subsection{Evaluation of point density}

This sub-section checks whether the point density can affect the accuracy of fitted curves. Here, 13 points (sparse) and 15 points (dense) are selected to fit the front and back curves with the same order. The results are shown in Figures 9 and 10. 


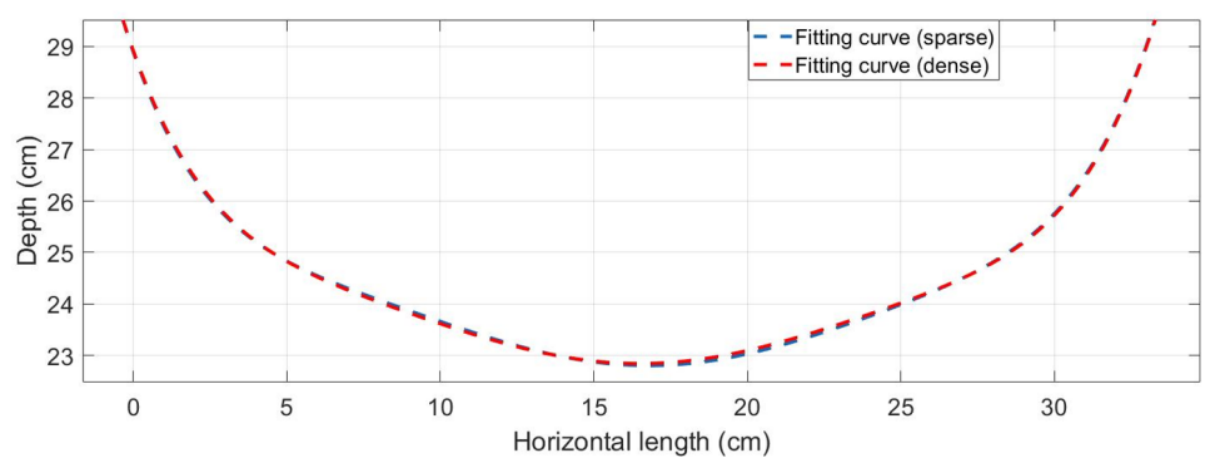

Figure 9. The front curves fitted with sparse and dense points

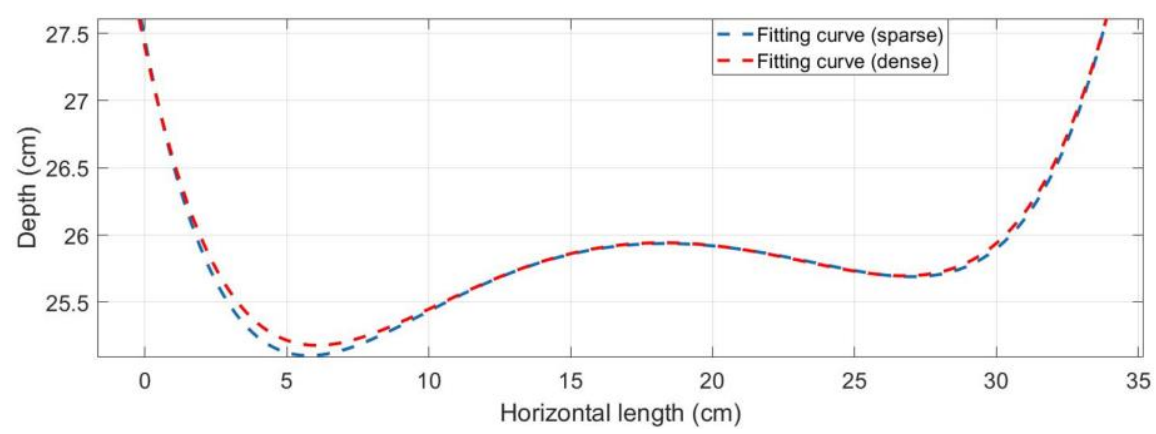

Figure 10. The back curves fitted with sparse and dense points

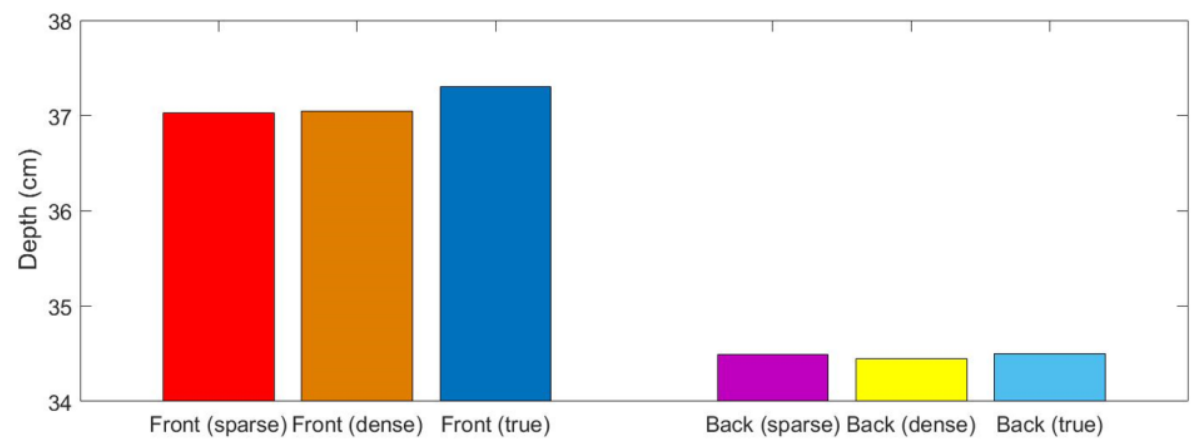

Figure 11. The length comparison between the curves fitted with the sparse and dense points 
Based on the results in Figures 9 and 10, the lengths of front curves fitted with sparse and dense points were compared, so did the back curves thus fitted. As shown in Figure 11, the front curve fitted with sparse points was $37.032 \mathrm{~cm}$, while the front curve fitted with dense points was $37.049 \mathrm{~cm}$. The front curve fitting accuracy increased by $0.046 \%$ due to the growth in point density. The back curve fitted with sparse points was $34.488 \mathrm{~cm}$, while that fitted with dense points was $34.444 \mathrm{~cm}$. The back curve fitting accuracy dropped by $0.128 \%$ as the points grew denser. Overall, the total fitting accuracy declined by $0.038 \%$ with the increase in point density.

The comparison shows that the excess points are not beneficial to the fitting accuracy. Coupled with the cost increase caused by the excess points, it is recommended to select a proper and few number of points for curve fitting.

Considering the above, the sixth-order function is employed to fit the curves with the estimated parameter of $10 \mathrm{~cm}$ (the real value is $9.7 \mathrm{~cm}$ ). In this case, the body perimeter was estimated as $81.52 \mathrm{~cm}, 99.98 \%$ of the ground truth value $(81.50 \mathrm{~cm})$.

\section{Discussion}

This paper develops an intelligent body measurement system that supports automatic body measurement. The experimental results indicate that the proposed system can achieve high accuracy and good robustness, and thus fulfill the demand of body measurement. The proposed system enjoys a simpler structure and a lower cost than any other popular measurement methods, be it laser scanning technology, stereo photography or structured light measurement. In our system, the depth information is captured by only two ultrasonic sensor arrays, and the measurement is highly accurate despite the low cost. Compared with the traditional manual measurement, the proposed measurement system is an ideal tool for garment customization because of its non-contact measurement mode, the fast measurement of multiple consumers and the high measuring accuracy. Of course, additional research is needed to further enhance the system performance facing a large group of consumers and determine the exact relationship between the estimated parameter and BWH information.

\section{Conclusions}

This paper puts forward an intelligent body measurement system capable of automatic and accurate measurement of the BWH data. In this system, the depth information between the body and the sensor is captured by ultrasonic sensor arrays; the depth data, coupled with array positions, are used to generate the space coordinates; the front and back curves are fitted based on the valid points of the space coordinates. Through repeated tests, the polynomial fitting was selected to fit the front and back curves. Then, the lengths of the fitted curves were obtained through integral operation. The experimental results show that the proposed system can achieve a measuring accuracy of $99.61 \%$. In the future, the system performance will be further improved facing a large group of consumers. 


\section{Acknowledgement}

Research of comprehensive guarantee system clothing and outfit for single pawn(police)

\section{Reference}

Akimoto T., Terada N., Yonezawa I., Muto O., Kawasaki T., Momomura R., Kaneko K. (2013). Development of measurement system for scoliosis using 3d camera. IEEE Transactions on Electronics Information Systems C, Vol. 133, No. 11, pp. 2082-2088. https://doi.org/10.1541/ieejeiss.133.2082

Biswas S., Ghoshal D., Hazra R. (2016). A new algorithm of image segmentation using curve fitting based higher order polynomial smoothing. Optik-International Journal for Light and Electron Optics, Vol. 127, No. 20, pp. 8916-8925. https://doi.org/10.1016/j.ijleo.2016.06.110

Brooks E. B., Thomas V. A., Wynne R. H., Coulston J. W. (2012). Fitting the multitemporal curve: A Fourier series approach to the missing data problem in remote sensing analysis. IEEE Transactions on Geoscience Remote Sensing, Vol. 50, No. 9, pp. 3340-3353. https://doi.org/10.1109/TGRS.2012.2183137

Cai Z., Liu X., Peng X., Yin Y., Li A., Wu J., Gao B. Z. (2016). Structured light eld 3d imaging. Optics Express, Vol. 24, No. 18, pp. 20324.

Cao S., Cao Y., Lu M., Zhang Q. (2014). 3d shape measurement for moving scenes using an interlaced scanning colour camera. Journal of Optics, Vol. 16, No. 12. https://doi.org/10.1088/2040-8978/16/12/125411/meta

Chen F., Chen X., Xie X., Feng X., Yang L. (2013). Fullfield 3d measurement using multicamera digital image correlation system. Optics Lasers in Engineering, Vol. 51, No. 9, pp. 1044-1052. https://doi.org/10.1016/j.optlaseng.2013.03.001

Cui H., Liao W., Dai N., Cheng X. (2012). An exible and rapid micro-adjustment algorithm for structured light $3 \mathrm{~d}$ measurement system with camera projector. Optik-International Journal for Light and Electron Optics, Vol. 123, No. 2, pp. 109-116. https://doi.org/10.1016/j.ijleo.2011.03.008

Floater M. S. (2006). High order approximation of rational curves by polynomial curves. Computer Aided Geometric Design, Vol. 23, No. 8, pp. 621-628. https://doi.org/10.1016/j.cagd.2006.06.003

Giachetti A., Lovato C., Piscitelli F., Milanese C., Zancanaro C. (2015). Robust automatic measurement of $3 \mathrm{~d}$ scanned models for the human body fat estimation. IEEE Journal of Biomedical Health Informatics, Vol. 19, No. 2, pp. 660-667. https://doi.org/10.1109/JBHI.2014.2314360

Guo L., Tian S., Jiang J. (2015). Estimation of channel mismatches in time-interleaved analogto-digital converters based on fractional delay and sine curve fitting. Review of Scientific Instruments, Vol. 86, No. 3, pp. 1618-615.

Haris M., Widyanto M. R., Nobuhara H. (2016). Firstorder derivative-based superresolution. Signal Image Video Processing, No. 1, pp. 1-8. https://doi.org/10.1007/s11760-016-0880$\mathrm{y}$ 
He Y., Cao Y. (2011). A composite-structured-light 3d measurement method based on fringe parameter calibration. Optics Lasers in Engineering, Vol. 49, No. 7, pp. 773-779. https://doi.org/10.1016/j.optlaseng.2011.03.013

Huang J., Xue Q., Wang Z., Gao J. (2016). Analysis and compensation for lateral chromatic aberration in a color coding structured light $3 \mathrm{~d}$ measurement system. Sensors, Vol. 16, No. 9. https://doi.org/10.3390/s16091426

Johnson R. T., Montgomery D. C., Jones B., Parker P. A. (2010). Comparing computer experiments for fitting high-order polynomial metamodels. Journal of Quality Technology, Vol. 42, No. 1, pp. 86-102.

Juki D., Scitovski R. (2005). Least squares fitting gaussian type curve. Applied Mathematics and Computation, Vol. 167, No. 1, pp. 286-298. https://doi.org/10.1016/j.amc.2004.06.084

Kim H. T., Jin K. C., Kim S. T., Kim J., Choi S. B. (2016). 3d body scanning measurement system associated with rf imaging, zero-padding and parallel processing. Measurement Science Review, Vol. 16, No. 2, pp. 77-86.

Kumar S., Furuhashi H. (2017). Long-range measurement system using ultrasonic range sensor with high-power transmitter array in air. Ultrasonics, Vol. 74, pp. 186-195. https://doi.org/10.1016/j.ultras.2016.10.012

Lin Y., Liu S. (2000). Law of exponentiality and exponential curve fitting. Systems Analysis Modelling Simulation, Vol. 38, No. 4, pp. 621-636.

Liu X., Zhao H., Zhan G., Zhong K., Li Z., Chao Y., Shi Y. (2016). Rapid and automatic 3d body measurement system based on a gpu-steger line detector. Appl Opt, Vol. 55, No. 21, pp. 5539-5547. https://doi.org/10.1364/AO.55.005539

Lrenz-Fonfria V. A., Padrs E. (2004). Curve fitting of Fourier manipulated spectra comprising apodization, smoothing, derivation and deconvolution. Spectrochimica Acta Part A Molecular Biomolecular Spectroscopy, Vol. 60, No. 12, pp. 2703-2710. https://doi.org/10.1016/j.saa.2004.01.008

Mohammed G. A., Hou M. (2016). Optimization of active muscle force length models using least squares curve fitting. IEEE Trans Biomed Eng, Vol. 63, No. 3, pp. 630-635. https://doi.org/10.1109/TBME.2015.2467169

Petrak S., Naglic M. M. (2017). Dynamic anthropometry defining protocols for automatic body measurement. Tekstilec, Vol. 60, No. 4, pp. 254-262. https://doi.org/10.14502/Tekstilec2017.60.254-262

Rabadan J., Guerra V., Rodrguez R., Rufo J., Lu-narivera M., Perezjimenez R. (2017). Hybrid visible light and ultrasound-based sensor for distance estimation. Sensors, Vol. 17, No. 2, pp. 330. https://doi.org/10.3390/s17020330

Renczes B., Kollr I., Dabczi T. (2016). Efficient implementation of least squares sine fitting algorithms. IEEE Transactions on Instrumentation Measurement, Vol. 65, No. 12, pp. 2717-2724. https://doi.org/10.1109/TIM.2016.2600998

Sekiya F., Sugimoto A. (2015). Fitting discrete polynomial curve and surface to noisy data. Kluwer Academic Publishers. https://doi.org/10.1007/s10472-014-9425-7

Shuan Y. C., Ding B. Y., Ouyang M. (2016). The review on the modified exponential model in the fitting of loading settlement curves of single pile. Applied Mechanics Materials, Vol. 501-504, pp. 892-904. https://doi.org/10.4028/www.scientific.net/AMM.501-504.892 
Sun Y., Wang T., Huang Y., Sun Y. (2017). Personalized recommendation system for sina microcomic users. Wireless Telecommunications Symposium, pp. 1-6. https://doi.org/10.1109/WTS.2017.7943533

Uhm T., Park H., Park J. I. (2015). Fully vision-based automatic human body measurement system for apparel application. Measurement, Vol. 61, pp. 169-179. https://doi.org/10.1016/j.measurement.2014.10.044

Wang Y. (2015). Non-contact human body measuring technology based on camera calibration technique. Journal of Fiber Bioengineering Informatics, Vol. 8, No. 4.

Wang Y. (2015). The laser rotating of non-contact body scanning system. Journal of Fiber Bioengineering Informatics, Vol. 8, No. 1, pp. 91-103. https://doi.org/10.3993/jfbi03201509

Zhu X. J., Wu X., Shi X., Xu B. G. (2017). Framework of personalized clothing visualization. International Journal of Clothing Science Technology, Vol. 29, No. 3. https://doi.org/10.1108/IJCST-07-2016-0080 
